\title{
Discussion on Construction of Tour Guide Talent Training Base in Vocational Colleges
}

\author{
Bo Wang \\ Luoding Polytechnic, Luoding, 527200, China
}

Keywords: Vocational college, Tour guide talent, Training base

\begin{abstract}
It has already developed into an emphasis of higher vocational education in China for strengthening the relationship between vocational colleges and enterprises and devoting to construction of tour guide talent training base in vocational colleges. This paper states the necessity to enhance the construction of tour guide talent training base in vocational colleges, analyzes relevant conditions about setting of tour guide talent training courses, and proposes several countermeasures for promoting the construction of tour guide talent training base in vocational colleges.
\end{abstract}

\section{Introduction}

Considering rapid development of tourist industry in China, the status of tourist industry becomes more and more important in national economic system in China. Nowadays, many Chinese places support tourist industry as an important economic growth point. At the same time, demands for tourism talents are continuously enlarged. Tourism major is available in many vocational colleges. Cultivation of tour guide is the most important orientation of major. Compared with other majors, tour guide is one of occupations closely integrated with the society. In the development course of Chinese tourist industry, the society has higher and higher requirements for the quality of tour guide. Cultivation of high-quality tour guide cannot be separated from actual demands of the present society. Teachers must realize the fact that accumulation of tourism experience is mainly from practice. However, tour guide is actually one of indispensably important contents. At the same time, it is also an important opportunity for vocational college students majoring in tourism to contact practical tourism work and cultivate practical skills.

\section{The necessity to enhance the construction of tour guide talent training base in vocational colleges}

Higher vocational education is a kind of education pattern with posts in the first line of production or management or post groups as major training objective. It has rather high requirements for the link of practice in course teaching. In recent years, educational departments at various levels proposed for many times important significance of construction of training base in vocational colleges. In 2010, the Ministry of Education formulated medium and long-term educational reform planning outline (2010-2020). It is defined in the outline that vocational education is an important mode for promoting China's economic development, accelerating employment, emphasizing people's livelihood and effectively solving the three agriculture-related issues in China. At the same time, vocational education is also an important method used to remit contradiction between supply and demand existing in China's labor force. Nowadays, status and function of tourist industry are continuously improved in overall economic development in China. The function of tourist industry in promoting China's economy, social employment and China's culture \& environment is continuously represented. Therefore, cultivation of high-quality tour guides conforms to development needs of higher vocational education in China. At the same time, it is also served as an urgent requirement for the development of China's economy. We should emphasize the cultivation of learners' operational ability according to relevant requirements for cultivation of tour guides in vocational colleges, persist in the principle of combining theory with practice, teaching with production and colleges with the society, and provide better practice teaching environment and conditions for students. To radically 
solve this puzzle, vocational colleges must form and complete the training base construction mechanism of cooperation between school and enterprise.

\section{Setting of training courses for tour guides in vocational colleges}

Firstly, training courses are offered upon cooperation between school and enterprise. Cooperation between school and enterprise can be regarded as one of distinctive features for school running of vocational colleges. At the same time, such cooperation is also a good method for development of vocational colleges in China. Various vocational colleges persist in the policy of integrating tour guide cultivation with market demand, and positively cooperate with domestic and international tourism enterprises. Therefore, there are lots of new training modes. Cultivation of tour guides in vocational colleges should start from the analysis on different posts, take cultivation of learners' vocational ability and application of professional knowledge as the objective, and formulate a tour guide cultivation training system together with enterprises. Under positive advocacy of this system, both school and enterprise should devote to jointly developing relevant training courses, forge some excellent courses for vocational college students, jointly implement project teaching, skill appraisal and performance evaluation, really integrate vocational qualification standards into teaching content, and emphasize the cultivation of vocational ability for vocational college students, so as to really realize the integration between cultivation objective and specific post demands in tourist industry. At the same time, we should also be based on the tour guide training system, and really realize whole-process quantization and delicacy management of training teaching.

Secondly, tour guide training program and standard are defined. To give full play to the function of training effect, we should offer several basic courses in the cultivation process of tour guides, analyze vocational ability of relevant employment posts, restructure the course system of various work programs and tasks, positively explore for training courses combined with learning and operating, practically take the present market demands and vocational work system as the principal orientation and vocational college students as subjects, emphasize the principal line of cultivation of learners' vocational ability and vocational quality, and form a new course system combined with applied theory explanation, special exercise and substituted post exercitation. For instance, the pattern of simulated tour guide can be adopted. Each teaching week includes 6 class hours in which 4 hours belong to campus teaching. Students can learn relevant basic knowledge on campus, supplemented with simulated drill. In the rest 2 hours, teaching tasks are performed in training base off campus. Teachers in the major of tourism and training instructors from enterprises should allocate relevant learning tasks together, and give scores after the completion of learning. After the completion of all class hours and passing two assessments on campus, this course is qualified. Similarly, this mode can also be used for reference in other courses like tourism business, travel agency cost control and travel agency management practice.

Thirdly, training teachers are specially selected. In the training process, professional tourism teachers should track the whole teaching process of vocational college students, closely combine the requirements of relevant technical fields and post groups, and comprehensively introduce vocational qualification standard for cultivation of tour guides, so as to smoothly finish relevant training tasks, correct and implement various issues in practical work process under elaborate guidance of training teachers, give expression to the feature of design according to actual needs of enterprises, and effectively prevent repetition of any courses on campus.

\section{Several countermeasures for promoting the construction of tour guide training base in vocational colleges}

\section{Flexibly allocate training time intervals according to specific needs of cooperative enterprises}

Tourist industry has obvious difference in slack season and busy season. In slack season, it is also possible for insufficient workload even for employees in tourism enterprises. Once it is in busy season, it is urgent for tourism companies to remit the puzzle of inadequate workers with many 
vocational college students for post substitution. In terms of arrangement of training time intervals, therefore, vocational colleges should consider special conditions of this major as much as possible, and reasonably arrange training intervals of intern students according to specific needs of tourism companies, so as to be helpful for better implementation of cooperation between school and enterprise. At the same time, it is also convenient for vocational colleges to find relevant training enterprises. For instance, a vocational college can adopt the mode of scattered training time, make the most of summer vacation, weekends, May Day, National Day and other vocations, negotiate with tourism companies in advance, and sign a short-term training agreement with these tourism companies, so as to realize smooth implementation of training for talents in the major of tourism.

\section{Attach importance to comprehensive ability training of vocational college students and shorten the time of adapting to post}

Tourist guide service is in industry directly providing service to tourists. It has rather high requirements for ability and quality of workers in various aspects. For intern students without practical work experience, however, it is rather difficult to adapt to this work in a short period. From the perspective of vocational colleges, therefore, the author thinks that the school should lay a solid foundation of basic knowledge for students, and shorten the time of internship as much as possible. At the same time, this is also the most important factor for tourism enterprises willing to accept intern students. For example, simulated training site and scenic spot can be used for field instruction, so as to make continuous improvement to the ability of vocational college students to comprehensively apply relevant knowledge about politics, economy, culture, philosophy, geography, religion and folk-custom and to basic skills of these students to give tour guide presentations. Field inspection should be made for major scenic spots in this region, so as to understand and get familiar with relevant conditions and main demands of tourists in a faster way.

\section{Complete tour guide training base operating system}

Firstly, we should complete the construction of benefit distribution system. Vocational colleges and tourist cities should seek for cooperation and coordination on the basis of voluntariness, equality and mutual benefit, and achieve the purpose of mutual development through complementary advantages. It is necessary for enterprises to make continuous improvement to market competitiveness by virtue of international talent advantages of enterprises, so as to solve the short-term shortage of human resources in training enterprises. Moreover, enterprises should also cultivate and give priority to excellent talents. Vocational colleges should comprehensively apply the platform of enterprise training base, so as to provide the realest and the most practical training tasks to teachers and students in the orientation of tourism, and cultivate abundant modern tour guides compatible with specific needs of tourism enterprises. Through training, vocational college students can obtain certain rewards from enterprises. At the same time, the adaptive period can be shortened as much as possible.

Secondly, we should complete the construction of safety guarantee system. Formation of safety guarantee system is the primary tasks of tour guide training base construction. It can provide high-quality guarantee for participation of students and teachers in the orientation of tourism in training. Vocational colleges should select surrounding travel agencies with good reputation as tour guide training base, and sign a cooperative agreement with these travel agencies. It should be definitely stated in the agreement that tourism enterprises should purchase accident insurance with a certain amount for each student participating in training. While organizing students to take part in training in scenic spots, vocational colleges should arrange school bus as much as possible, and purchase relevant accident insurance for teachers and students participating in training, so as to guarantee safety of various links to the maximum extent. Thus, both students and teachers can obtain insurance claims with a certain amount in case of an accident, so as to minimize relevant losses. Safety guarantee can minimize relevant risks, and define liabilities for claim. At the same time, we should also list the content of flexible post substitution into the training plan of this major, and promptly arrange students for participation according to the agreement signed with cooperative travel agencies. 
Thirdly, we should complete the construction of constraint system. Rights and obligations of both parties should be constrained by the cooperative agreement signed with training enterprises, so as to guarantee mutual benefit of both parties and stable long-term operation of cooperation. Moreover, we should list training into the credit management system in vocational colleges, and apply credit or training enterprise assessment in constraining students' participation in training, so as to avoid absence and other bad performance of learners at training base. On this basis, students' performance in training base should be also listed into the assessment. Students with excellent performance should be provided with the priority to excellence assessment and work recommendation. At the same time, teachers in the major of tourism should train in the same base with enterprises for the convenience of communication and connection between students and teachers. Teachers should promptly find relevant difficulties facing their students in the training process, and help them to conquer these difficulties.

\section{Expand new approaches for construction of training base with school-enterprise cooperation as the carrier}

According to the author, development of tour guide training base should take vocational colleges as the carrier, and make better improvement to training quality of vocational college students through more approaches. Vocational college belongs to teaching competent organization. It shoulders the important task for construction of vocational college training base. It is more credible for connection with tourism companies organized by vocational colleges. Thus, training enterprises connected by vocational colleges usually keep long-term contact with colleges. Moreover, vocational colleges should also use order-like teaching and whole-course teaching to improve the connotation of training. This pattern can realize integration between training and employment. At the same time, it can also provide more diversified training programs for students. For instance, vocational college students can participate in short-term training in enterprises in non-stipulated time of internship, so as to realize the combination of theoretical knowledge with practical skills. Besides, students can independently divide themselves into different groups, and seek for training enterprises through the mode of grouping. For a small number of students, it is helpful for tourism companies to accept interns. Certainly, emphasis should be laid on off-campus safety prevention for students under such mode.

\section{Conclusion}

To sum up, construction of tour guide training base is a long-term systematic project in vocational colleges. How to construct a training base operating mode compatible with development of China's higher vocational education under new situation already becomes one of important topics facing many vocational colleges. However, tour guide training base is even an important carrier for cultivation of practice ability and innovation ability of vocational college students majoring in tourism. Its operating ability is one of important standards for scientific research and management ability in this major. In further work, therefore, we should continuously intensity system construction and complete management and construction of tour guide training base, so as to quickly form a modern training pattern compatible with tourism education in vocational colleges.

\section{Acknowledgments}

This paper is the phased achievement for the topic (GD14DL04) of the "12th Five-Year Plan" of philosophy and social science in Guangdong Province and for the topic of Advanced Tour Guide Business of Guangdong AIB Polytechnic College at the level of educational reform research institute.

\section{References}

[1] Cao Xia, Discussion on Relevant Issues about Construction of Training Base, Science \& Technology Information, 2009 (19); 
[2] Li Qiaoping, Zhu Lin and Wang Lihua, Discussion on Relevant Issues Existing in the Process of Comprehensive Training Course Setting in Vocational Colleges, China Adult Education, 2010 (1);

[3] Di Baorong, Jin Yu and Liu Feng, Research on Training Mode of Tourism Education Practical Ability in Developed Countries, Journal of Tourism Development, 2012 (1);

[4] Chen Youjun, Research on Comprehensive Training Course Development Led by Task and with Students as Main Subjects, Management \& Technology of SME, 2011 (6);

[5] Hou Yuanlin, Reflection and Innovation of Professional Practice in Tourism Management Major in Colleges and Universities, Tourism Tribune, 2014 (31) 